\title{
Factors Motivating the Adoption of e-Learning Technologies
}

\author{
Yining Chen, Harold T. Little Jr., Mark T. Ross and Qin Zhao \\ Department of Accounting, Western Kentucky University, College Heights Blvd. Bowling Green, \\ Kentucky, USA
}

\begin{abstract}
This study uses expectancy theory in an experimental setting to explain student motivation in adopting e-Learning technology. Data gathered from 173 students, having classroom exposure to eLearning technologies, suggest that expectancy theory is appropriate for evaluating and understanding a student's motivation to adopt an e-Learning technology. On average, students considered information acquisition as the most attractive outcome of an e-Learning technology. Further, empirical evidence suggests that e-Learning technology adoption is more likely to succeed 1) when the technology is perceived by students to be in their best interest, and 2) when students perceive that reasonable efforts will result in successful adoption.
\end{abstract}

Keywords: e-Learning, motivational factor, expectancy theory, technology adoption.

\section{Introduction}

Advances in information technology have created additional options for today's education (Yang \& Arjomand, 1999). Corporate and campus agendas have started to recognize e-Learning as having the potential to transform people, performance, knowledge and skills (Henry, 2001). Major colleges and universities race to develop online course capability in a rapidly emerging cyber education market (Love \& Fry, 2006); every major institution of higher education in the US offers at least a portion of their classes over the Internet, and the use of a virtual learning environment has become commonplace. As the demand for lifelong learning increases and the technological improvements enable us to more closely simulate a live classroom, the growth in eLearning will continue to explode (Burke \& Slavin, 2000).

E-Learning, also referred to by such names as online learning, virtual learning, distance learning, computer-based training and Webor Internet-based training, comprises all forms of internet supported learning and teaching. Henry (2001, page 249) defines eLearning as the appropriate application of the Internet to support the delivery of learning, skills and knowledge in a holistic approach not limited to any particular courses, technologies, or infrastructures. eLearning provides a student-centered learning environment by delivering knowledge on-demand with up-to-theminute information (Leung \& Li, 2006). The unarguable upside of e-Learning is that it requires little or no face-to-face contact time, therefore is more cost-effective. Via technology, teacher and students, while physically separated, are intellectually connected (Burke \& Slavin, 2000).

To enable students to communicate with their instructor and other participants in both synchronous and asynchronous formats, e-Learning relies heavily on communication technologies. In fact, most courses with e-

Copyright (C) 2012 Yining Chen, Harold T. Little Jr., Mark T. Ross and Qin Zhao. This is an open access article distributed under the Creative Commons Attribution License unported 3.0, which permits unrestricted use, distribution, and reproduction in any medium, provided that original work is properly cited. Contact author: Yining Chen E-mail: yining.chen@wku.edu 
Learning components use mechanisms, such as bulletin boards, chat-rooms, e-mail and video conferencing through which students can communicate with the teacher and other students whenever their schedule allows. Since skills and knowledge transfer activities are conducted online, successful application and implementation of e-Learning technologies is essential for learning effectiveness.

This study uses expectancy theory to explain student motivation in adopting e-Learning technology. Data gathered from 173 students with e-Learning experience suggest that expectancy theory is appropriate for evaluating and understanding student motivation in adopting e-Learning technology. On average, students identify information acquisition as the most attractive outcome of e-Learning technology. In addition, empirical evidence confirms that e-Learning technology adoption is more likely to succeed 1) when the technology is perceived by students to be in their best interest and 2) when students perceive that reasonable efforts will result in successful adoption.

\section{Literature Review}

Consistent with an emerging area of research that is still in its developmental stage, a significant amount of e-Learning literature has focused on what e-Learning is, who delivers it, who benefits from it, and the methods in which it is delivered. As a result, there is an overwhelming amount of information on the logistics, infrastructure and technologies of e-Learning (Hopey \& Ginsburg, 1996). Writings on structural changes resulting from partnering relationships among the major players and with the society as a whole for both delivering and acquiring e-Learning are throughout the literature (Wreden, 1997). Given the need to incorporate new technologies into the classroom, it is important to understand the impact of eLearning on the teaching-learning environment from the student's perspective (Love \& Fry, 2006).

Many argue that the technologies alone cannot guarantee the successful implementation of e-Learning (Ignatius \& Ramayah, 2005). Student behavior and responses toward the technology will determine whether implementation is successful. Along this research line, studies on a specific institution's or organization's model of e-Learning and its impact on participants abound (Hall, 1996; Harrod \& Townsend, 1998; Nixon \& Helms, 1997; Wildstrom, 1997).

\section{E-Learning Experience and Student Satisfaction}

Among the studies that examine pedagogical issues, many look into the effectiveness and quality of e-Learning. Those with favorable results argue that online education (1) provides students with better and faster access to information; (2) presents information from multiple perspectives; (3) enables students to control the learning process; (4) allows for more individualized instruction; (5) accommodates a wide range of learning styles; and (6) increases student satisfaction with their courses (Baker, Hale, \& Gifford, 1997; Follows, 1999; Navarro \& Shoemaker, 2000). Supporters of online learning argue that new computer-assisted technologies can promote not only greater student involvement in learning, but also greater individual responsibility for learning. Despite the claims that e-Learning can enhance the quality of education, Dowling et al. (2003) argue that providing learning materials online results in improved learning outcomes only for specific forms of summative assessment. Mayes (2002) questions whether e-Learning is simply a support mechanism for existing learning methods.

The most prominent criticism of e-Learning is its lack (or complete absence) of crucial personal interactions, not only between students and teachers, but also among fellow 
students as well. Some researchers observe a depersonalization of the learning process and a hollow pedagogy that stresses memorization rather than synthesis and analysis (Burdman, 1998; Young, 1997; Monaghan, 1995). Conversely, others believe that e-Learning creates a more balanced interactive learning environment through the use of collaboration tools such as discussion boards, virtual chat rooms and interactive tutorials that can facilitate the studentteacher and student-student relationships (O'Leary, 2002). Although it may not be the best channel for improving interaction, eLearning does have "a role in facilitating new participative, mutual, and more conversational student-teacher relations and more supportive and engaged student/student relations" (Ramsey, 2003, p.31).

While there exists a plethora of normative and theoretical research on student interactions and e-Learning, empirical research examining factors that influence student receptivity to e-Learning using potential users of e-Learning technology has been relatively unexplored (Anakwe, Kessler, \& Christensen, 1999). Influential implementation and environmental factors identified by prior studies include technical support (Armstrong, 2002), past experience with e-Learning (Holscherl \& Strubel, 2000), preparation for use of computer-based resources (Taylor, 2000), occupational experience (Durling et al, 1996), gender (Ford \& Miller, 1996) and cognitive style (Dufresne \& Turcotte, 1997). Galitz (2002) acknowledges that such a wide range of influential factors makes the design and implementation of an e-Learning curriculum a complex task.

\section{Logistics, Infrastructure and Technologies} of e-Learning

Extending the acquisition of knowledge from a classroom-restricted pedagogy to an online model provides broader opportunities of instruction with a more flexible environment, in terms of time, logistics, content and delivery (Collis \& Moonen, 2001). Among those studies that examine e-Learning technologies, the emphasis has been on applying internet technologies to integrate many diverse instructional resources and events into powerful and cohesive learning paths (Henry, 2001). Love and Fry (2006) conclude from their empirical study that eLearning is regarded as value-added and students are successfully engaged only when the elements of the learning process are constructively aligned and integrated.

E-Learning processes, inventions and methods are being used for purposes such as adaptive delivery of educational content, individualizing learning materials, dynamic feedback, cognitive diagnosis, score reporting and course placement (Scalise et al., 2007). The specific learning objectives and applications that e-Learning technologies are expected to support include:

- Instruction (lecture, demonstration, webinars, literature, ebooks);

- Collaboration (virtual chat room, discussion board, study group, mentored exercise, instant message);

- Practice (interactive tutorials, online labs, simulation, role playing schemes); and

- Assessment (performance testing, proficiency evaluation, feedback mechanism).

A number of recent e-Learning studies offer guidelines for instructional design, teaching strategy and multimedia selection. De Lange et al. (2003) argue that student motivation is a product of the interest generated by the instructional medium used in the delivery of the subject matter. Frey et al. (2003) assert that media combination used to present learning materials is just as important as the style of learning adopted by students. Follows (1999) contends that innovative and high-level technology mediums can stimulate learners, increase motivation and enhance learning outcomes. According to Sun \& 
Cheng's (2007) media richness theory, the more complex and difficult the course content, the richer the media should be. In contrast, Clark (1983) suggests that media are merely vehicles that deliver instruction; and do not necessarily enhance learning outcomes or student achievement. However, it should be noticed that media in the 1980's were not as developed, readily available, or capable as compared to that of today.

Central to the success of an e-Learning initiative is matching technology to the needs of the targeted learning environment and its users. Empirical results of Hornik, Johnson \& $\mathrm{Wu}$ (2007) indicate that when there was dissidence between technological support for learning and users' epistemological beliefs, course communication, course satisfaction and course performance were reduced. $\mathrm{Xu}$ and Wang (2006) propose the employment of intelligent agent technology to achieve personalization and effectiveness in the eLearning environment. Clerehan et al. (2003) suggest that well-designed e-Learning initiative should include links that enable learners to build on their existing knowledge and develop new learning strategies. This allows for an increase in student choices of place, time and style of learning as well as the capacity for critical thinking and analysis. The effectiveness and scalability of the eLearning paradigm, however, can only be achieved through the integration of pedagogically intelligent approaches using lesson preparation tools that are well accepted by both student and teacher (Hameed et al., 2007).

To be successful in conducting learning activities, e-Learning is heavily influenced by various technologies and their successful implementation. There exists a profusion of technologies that enable the realization and expansion of e-Learning in terms of its course-content delivery. Nevertheless, it is not the technologies alone that ensure successful implementation. Student behavior and responses to the technology will determine whether implementation is successful (Ignatius \& Ramayah, 2005). Implementation success is measured by students' knowledge of the technology, attitudes toward the technology, normative consensus among participants regarding the value of the technology and actual use of the technology (Chen et al, 2003). Technological implementation will succeed only when it is perceived by participants to be in their best interest in terms of ease of use and usefulness (Griffith, 1996). While several prior studies have examined the effect of eLearning and its technologies on student performance and learning effectiveness, relatively few studies have looked into student attitudes and learning behavior. Both Sun \& Cheng (2007) and Frey et al. (2003) suggest that further research is needed to gain a better understanding of student learning behavior.

\section{Expectancy Theory}

Vroom's (1964) expectancy theory is considered one of the most promising conceptualizations of individual motivation. Prior studies have suggested that adoption of an expectancy theory approach should enhance the understanding of users' attitudes and behavior (DeSanctis, 1983; Robey, 1979; Zmud, 1980). This study examines the application of expectancy theory by measuring user attitudes toward eLearning technologies and behavioral intention (motivation) to adopt e-Learning technology. Figure 1 depicts how expectancy theory can be applied in measuring the successful implementation of an e-Learning technology. 


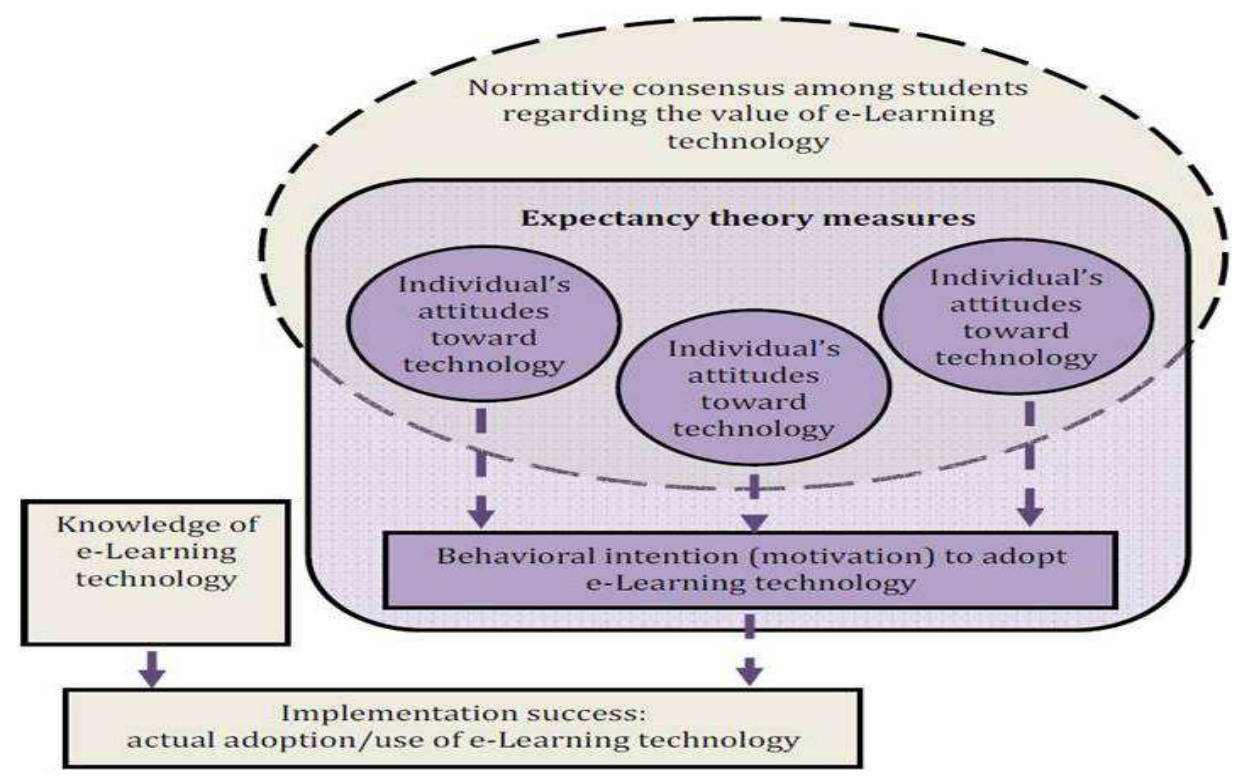

Figure 1. Successful Adoption of an e-Learning Technology

Expectancy theory was originally developed by Vroom (1964) and has served as a theoretical foundation for a large body of studies in psychology (Brownell \& McInnes, 1986), organizational behavior (Hancock, 1995) and management accounting (Snead \& Harrell, 1995; Geiger \& Cooper, 1996). Expectancy models are cognitive explanations of human behavior that cast individuals as active, thinking and predicting creatures in their environment. Individuals continuously evaluate outcomes of their behavior and subjectively assess the likelihood that each of their possible actions can lead to various outcomes.

According to Vroom, expectancy theory is comprised of two related models: the valence model and the force model. The valence model captures the perceived attractiveness, or valence, of achieving a primary outcome by aggregating the valences of associated outcomes. The force model maintains that the motivational force influencing a person to act is equal to the valence of the outcome multiplied by the expectancy that the act/effort will result in the outcome (Campbell et al., 2003). In this study's application of expectancy theory, subjects first use the valence model to evaluate outcomes of the e-Learning technology and then subjectively assess the likelihood that these outcomes will occur. Next, by placing intrinsic values (or weights) on the various outcomes, they evaluate the overall attractiveness of the e-Learning technology. Finally, they apply the force model to determine the amount of effort they are willing to exert to adopt the technology. This effort level is determined by the product of the attractiveness generated by the valence model (above) and the likelihood that the effort will result in a successful adoption of the technology. Based on this systematic analysis, the subjects determine the amount of effort they would be willing to exert in using the e-Learning technology. Figure 2 illustrates the application of expectancy theory to the decision making process (i.e., valence and force models). 


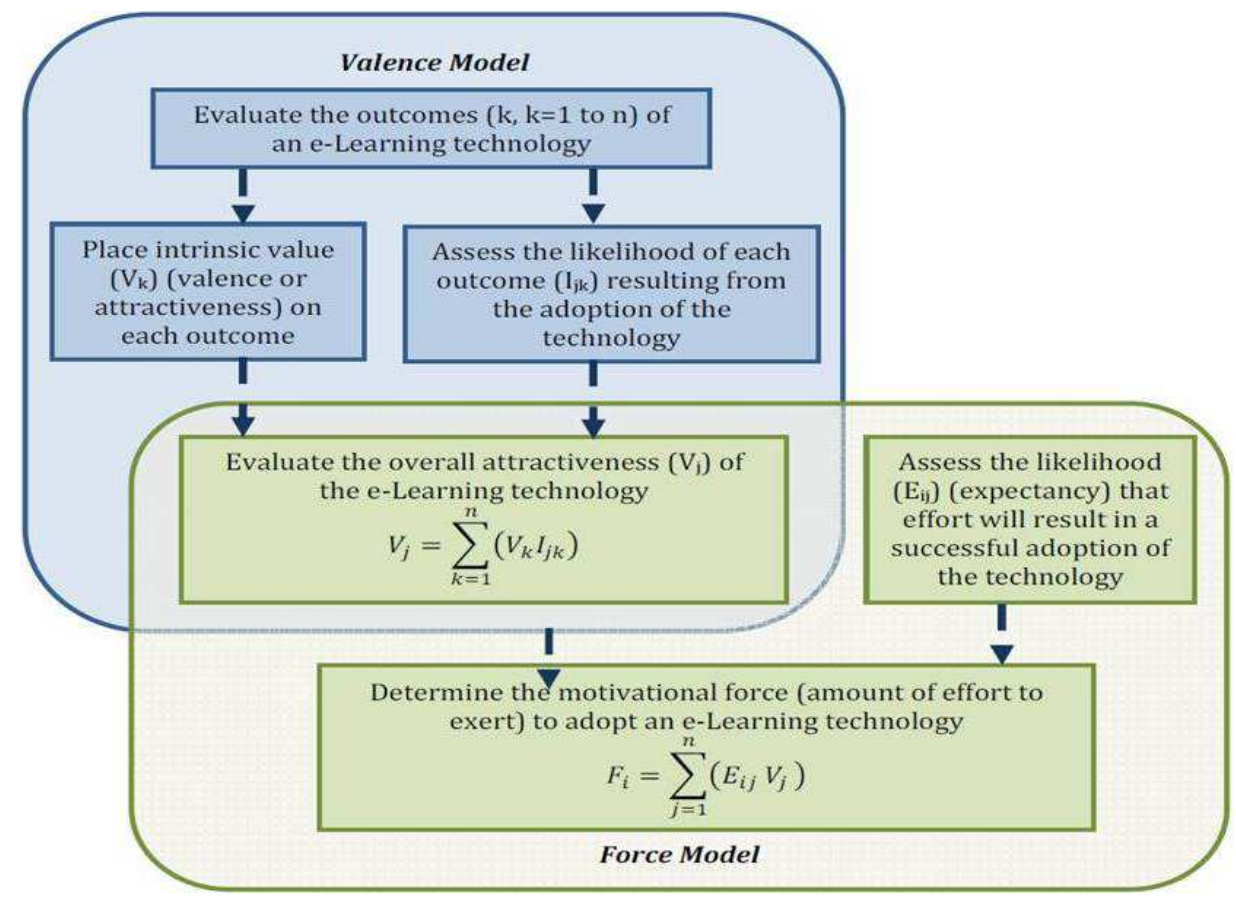

Figure 2. Application of Expectancy Theory in e-Learning Technology Adoption Decision Making

\section{Research Question and Methodology}

The general research question examined by this study is "Can the valence and force models of expectancy theory explain the motivation of a student to utilize an eLearning technology?" Specifically, under the valence model, the researchers investigate the impact of the potential outcomes of eLearning technology upon student motivation to adopt such technology. The four outcomes of e-Learning technologies tested by this study are: (1) enriched information acquisition, (2) increased participation and involvement in knowledge construction, (3) enhanced collaboration and communication, and (4) improved feedback and grade reporting. These outcomes correspond to the functions suggested in the literature (e.g., instruction, collaboration, practice and assessment) that e-Learning technologies are expected to support (Scalise et al., 2007; De Lange et al., 2003; Follows, 1999). Under the force model, the researchers examine the extent to which the difficulty of adopting an e-Learning technology will affect student motivation to utilize the technology.

\section{Research Design}

Murray and Frizzier (1986) suggest that the appropriate tests of the within-person focus of expectancy theory should involve comparing measurements of the same individual's motivation under different circumstances. As suggested, this study incorporates a well-established withinperson methodology originally developed by Stahl \& Harrell (1981) and later proven to be valid by other studies (e.g., Snead \& Harrell, 1995; Geiger \& Cooper, 1996). This methodology uses a judgment modeling decision exercise that utilizes sets of outcomes which are used to arrive at a particular judgment or decision. Multiple sets of these outcomes are presented with each set having a unique combination of probabilities assigned to outcomes. A 
separate judgment is required for each unique combination of outcomes. ${ }^{1}$

Utilized in this study is a one-half fractional factorial design with eight unique combinations of the outcomes $\left(2^{4} \times \frac{1}{2}=8\right.$ combinations), given that $16 \quad\left(2^{4}\right)$ combinations of the four outcomes and two levels $(10 \%$ and $90 \%)$ of likelihood are possible. Each of the eight combinations of outcomes is then presented at two levels $(10 \%$ and $90 \%)$ of expectancy to obtain 16 unique cases ( 8 combinations $\times 2$ levels of expectancy $=16$ cases $){ }^{2}$ These multiple cases allow unique measurement of behavioral intentions for each case, which is a prerequisite for the within-person application of expectancy theory (Snead \& Harrell, 1995). The instructions for the instrument and a sample case are provided in the Appendix. ${ }^{3}$

Each of the 16 cases requires two decisions. The first decision (Decision A) corresponds to the valence model and represents the overall attractiveness of adopting the eLearning technology, given the likelihood $(10 \%$ or $90 \%)$ assigned to each of the four outcomes that would result from the adoption. The second decision (Decision B) corresponds to the force model and reflects the amount of effort the participant is willing to exert to adopt the e-Learning technology, based on the prior valence condition (Decision A, F1) and the expectancy (10\% or $90 \%$ ) that if the participant exerts a great deal of effort, success in using the technology (F2) would occur. An eleven-point response scale, with a range of -5 to 5 for Decision $A$ and 0 to 10 for Decision $B$, is used to capture each of the subject's responses. Negative five represents "very unattractive" for Decision A and positive five represents "very attractive." For Decision B, zero represents "zero effort" and ten represents a "great deal of effort."

\section{Subjects}

Subjects used in the study were 173 undergraduate students enrolled in ten business courses taught by five instructors at a mid-sized, mid-western, state university. ${ }^{4}$ The number of females and males were 96 and 77, respectively. A total of 169 students $(97.7 \%)$ had used an e-Learning technology in a prior or current course. The students represent 31 academic major programs, with 109 having business majors. On average, the students were 22 years old, had a GPA of 3.26, and had 10.24 years of experience using a personal computer or other computer-based systems. These students are appropriate as subjects for this study, because (1) they have classroom exposure to an e-Learning technology, and (2) they are eligible users since e-Learning technologies (i.e., Blackboard, WileyPlus and McGraw-Hill Connect) are made available for their use in learning activities.

\section{Experimental Controls}

Pearson's correlations between $\mathrm{R}^{2}$ values of valence and force models and select demographic information (rank, gender, age, GPA, prior experience using e-Learning technologies) are used to test associations between empirical results and student background. Students were asked to evaluate 16 hypothetical e-Learning technology cases. They were not asked to evaluate the eLearning technologies with which they had experience. Therefore, the student's background should not affect their responses. Non-significant correlations between students' backgrounds (i.e., rank, gender, age, GPA, prior experience using e-Learning technologies) and $\mathrm{R}^{2}$ values for valence and force models would indicate that the students are able to respond to experimental questions objectively and without bias.

\section{Result and Discussion}

\section{Attractiveness of e-Learning Technology}

The valence model of expectancy theory can explain a student's perception of the attractiveness of adopting an e-Learning technology. Each student's perception is assessed through the use of multiple regression analysis, where Decision A serves 
as the dependent variable and the four outcomes serve as independent variables. The resulting standardized regression coefficients represent the relative importance (attractiveness) of each outcome to the student in arriving at Decision A. The mean adjusted $-\mathrm{R}^{2}$ of the regressions and the mean standardized betas of each outcome are presented in Table 1. Detailed regression results for each student are not presented and are available on request.
As shown in Table 1, the mean adjusted- $\mathrm{R}^{2}$ of the individual regression models is .6788 . The mean adjusted- $\mathrm{R}^{2}$ represents the percentage of total variation in the responses explained by the multiple regressions. Thus, these relatively high mean adjusted $-R^{2} S$ indicate that the valence model of expectancy theory explains much of the variation in student perception of the attractiveness of adopting an e-Learning technology. Among the 173 individual regression models, 163 are significant at a .05 level.

Table 1: Valence Model Regression Results *

\begin{tabular}{|l|l|l|l|l|l|}
\hline & $\begin{array}{l}\text { Sample } \\
\text { Size }\end{array}$ & Mean & $\begin{array}{l}\text { Standard } \\
\text { Deviation }\end{array}$ & Range of Reponses & $\begin{array}{l}\text { Frequency } \\
\text { of } \\
\text { Significance } \\
\text { at } .05 \text { level }\end{array}$ \\
\hline Adjusted R & & & & \\
\hline \multicolumn{2}{|l|}{ Standardized Beta Weight: } & .6788 & .1679 & .1523 to .9662 & $163 / 173$ \\
\hline V1 & 173 & .4419 & .2289 & -.8723 to .8277 & $132 / 173$ \\
\hline V2 & 173 & .3667 & .2124 & -.4495 to .8887 & $114 / 173$ \\
\hline V3 & 173 & .2504 & .2617 & -.5963 to .8127 & $90 / 173$ \\
\hline V4 & 173 & .3923 & .2302 & -.3889 to .9741 & $122 / 173$ \\
\hline
\end{tabular}

* Results (i.e. mean, standard deviation, range and frequency of significant at .05) of individual withinperson regression models are reported in this table.

V1: valence of information acquisition facilitated

V2: valence of participation in knowledge construction promoted

V3: valence of collaboration and communication supported

V4: valence of feedback and score reporting provided

The standardized betas of the four outcomes are significant at the .05 level for a majority (163 out of 173) of the students. These results imply that all four outcomes are important factors to a majority of the students in determining the attractiveness of an e-Learning technology. Although all four outcomes are important, some outcomes are more important than others. It is the mean of these standardized betas that explains how students, on average, assess the attractiveness of potential outcomes resulting from an e-Learning technology. Students, on average, place the highest valence on outcome V1 (information acquisition and facilitation). The other valences, in descending order of importance, are V4 (feedback, diagnosis and score reporting), V2 (participation in knowledge construction) and V3 (collaboration and communication). Thus, students perceive that acquisition, exchange and analysis of information are collectively the most attractive outcome of an e-Learning technology and that supporting collaboration among fellow students and professors is the least attractive outcome. Dynamic feedback, cognitive diagnosis, score reporting collectively and increased participation and involvement in knowledge construction collectively have intermediate rankings.

\section{Motivation to Use e-Learning Technology}

The force model is effective in explaining a student's motivation in adopting an eLearning technology. Multiple regression analysis is used to examine the force model, 
using the student's level of effort exerted to adopt e-Learning technology in class activities (Decision B) as the dependent variable. The two independent variables are (1) student's perception of the attractiveness of the e-Learning technology (Decision A), and (2) the information about expectancy probabilities $(10 \%$ or $90 \%)$, which is provided by the "Further Information" sentence in the test instrument (see Appendix I). ${ }^{5}$ Results of the force model are summarized in Table 2 .

Table 2: Force Model Regression Results*

\begin{tabular}{|l|l|l|l|l|l|}
\hline & $\begin{array}{l}\text { Sample } \\
\text { Size }\end{array}$ & Mean & $\begin{array}{l}\text { Standard } \\
\text { Deviation }\end{array}$ & Range of Reponses & $\begin{array}{l}\text { Frequency of } \\
\text { Significance } \\
\text { at .05 level }\end{array}$ \\
\hline Adjusted R ${ }^{2}$ & 173 & .7468 & .1777 & .2349 to .9771 & $169 / 173$ \\
\hline \multicolumn{5}{|l|}{ Standardized Beta Weight: } \\
\hline F1 & 173 & .5920 & .2645 & -.0598 to .9778 & $157 / 173$ \\
\hline F2 & 173 & .4715 & .3522 & -.2776 to .9882 & $123 / 173$ \\
\hline $\begin{array}{l}\text { * Results (i.e. mean, standard deviation, range and frequency of significant at .05) of individual } \\
\text { within-person regression models are reported in this table. }\end{array}$ \\
$\begin{array}{l}\text { F1: weight placed on attractiveness of the e-Learning technology. } \\
\text { F2: weight placed on the expectancy of successfully using the technology. }\end{array}$ \\
\hline
\end{tabular}

The mean adjusted- $\mathrm{R}^{2}(.7468)$ indicates that the force model sufficiently explains student motivation in adopting the e-Learning technology. The mean standardized regression coefficient F1 (.5920) and coefficient F2 (.4715) measures the impact of the overall attractiveness of the e-Learning technology and the expectation that a certain level of effort leads to successful adoption of the technology, respectively. Results indicate that both factors, the attractiveness of the eLearning technology (F1) and the likelihood that the effort exerted by the students will lead to successful adoption (F2) are equally important to student motivation.

\section{Experimental Controls}

Table 3 presents Pearson's correlations between adjusted- $\mathrm{R}^{2}$ values of valence and force models and selected demographic information (i.e., rank, gender, age, GPA and prior experience using e-Learning technologies). There is no significant correlation (at the .05 level), suggesting that student perception of the attractiveness of the e-Learning technology and motivation to adopt the technology are not correlated with student demographic variables or with prior experience in e-Learning technology. These results confirm that the students being used as subjects are appropriate for this study. ${ }^{6}$

Table 3: Pearson's Correlation Coefficients and (P-Values)

\begin{tabular}{|l|l|l|l|l|l|}
\hline & Rank & Gender & Age & GPA & Experience \\
\hline Adj-R ${ }^{2}$ & 0.0189 & 0.1411 & -0.0328 & 0.0928 & -0.0117 \\
Valence & $(0.8059)$ & $(0.0648)$ & $(0.6698)$ & $(0.2260)$ & $(0.8791)$ \\
\hline Adj-R ${ }^{2}$ & -0.0218 & -0.0334 & -0.0716 & -0.0251 & -0.0921 \\
Force & $(0.7762)$ & $(0.6639)$ & $(0.3504)$ & $(0.7437)$ & $(0.2294)$ \\
\hline
\end{tabular}

\section{Limitations and Conclusions}

Through the application of expectancy theory, this study provides a better understanding of the behavioral intention (motivation) of the adoption of an e-Learning technology. The empirical results show that preferences exist for potential outcomes of e-Learning technologies and that these preferences are consistent across individuals. On average, 
facilitating acquisition, exchange and analysis of information collectively is considered the most attractive outcome of e-Learning technology. As a result, those adopting an eLearning technology to facilitate information acquisition in performing course work should be highly motivated to exert effort to adopt such a technology. Since successful implementation of e-Learning technology is an essential antecedent to the effectiveness of e-Learning, student preference and motivation must be considered thoughtfully when the technology is implemented.

The researchers provided empirical that technology adoption in e-Learning is more likely to succeed when it is perceived to be in the adopter's best interest, and when successful adoption results from reasonable efforts. When uninformed of the potential benefits of the e-Learning technology or when no visible results from the adoption efforts are seen, adopters cease efforts to adopt the technology. In practical terms, it has been shown that elements of expectancy theory can be utilized early in the design phase of product development to access users' intention to adopt e-Learning technology. In order to maximize implementation success (i.e., technology usage and user acceptance), software developers and designers need to incorporate and stress the importance of the favorable attributes (outcomes) into their eLearning technology products. Furthermore, software developers should gauge their own efforts to achieve these outcomes according to each outcome's relative importance.

Toward the goal of motivating students to adopt an e-Learning technology, the following practical suggestions are offered. First, select an e-Learning technology that students perceive to be useful (i.e., consistent with what students perceive to be in their best interest). Consider listing the benefits and outcomes of the technology in user's manuals and emphasizing them in training sessions. If the benefits and outcomes are consistent with students' interests and they believe that their effort to adopt will truly result in these benefits, then students will assign a high value to the technology. Second, provide training that increases the students' chances for success in adopting the technology. In training sessions, use examples of previous student success resulting from adoption. This would improve students' perceptions that they too can be successful, thus increasing their motivation to adopt the technology. Third, reward technology adoption. Collect and disseminate statistics that show a positive correlation between the frequency of using the eLearning technology and course work performance. Objective statistical evidence can emphasize to students that adoption of the e-Learning technology does lead to competency in comprehension and performance of course work.

As with most experimental research, limitations do exist. First, the selection of subjects was not a random process. Students became subjects by virtue of being enrolled in the classes selected and all subjects come from only one institution. Consequently, extrapolation of the findings to other groups and settings should be made with caution. Second, students were not given the opportunity to provide input on the outcomes that motivate them to adopt the eLearning technology. In the instrument, four possible outcomes were given to students. Third, extreme levels of instrumentality and expectancy (10 percent and 90 percent) were assigned. This did not allow for testing of the full range within the extremes. In another sense, such extremes may not exist in actual practice.

In summary, this study successfully applies a behavioral theory, i.e., expectancy theory, to address a pedagogic technology implementation. Furthermore, the findings provided herein, (1) helps to close the gap between the capabilities of an e-Learning technology and the extent to which it is used; (2) responds to assertions in previous research that the gap can be better explained by behavioral elements rather than by technical attributes; and (3) seeks to identify 
student-specific factors that should be considered when e-Learning technologies are designed or adopted. Future research should revalidate the application of expectancy theory in different contexts. Various factors such as social norms, course nature (e.g., structure and content) and grading schemes can be examined to determine their impact on the valence and force models. Continuing the line of several prior studies (Lucas \& Spitler, 1999; Szajna \& Scamell, 1993), the relationship among attitude (i.e., perceived technology quality, perceived usefulness and perceived ease of use), intention and actual use of e-Learning technologies requires further validation. The ultimate goal of this line of research is to gain a more rigorous and consistent insight into the understanding of the effectiveness of e-Learning technology, as well as the ability to explain and predict user acceptance of the technology.

\section{End Notes}

1. An advantage of the within-person methodology is the control of extraneous variables. Since the analysis is within each subject, extraneous variables such as GPA, age, experience, etc. are controlled.

2. According to Montgomery (1984, p. 325), "if the experimenter can reasonably assume that certain high-order interactions are negligible, then information on main effects and loworder interactions may be obtained by running only a fraction of the complete factorial experiment." A one-half fraction of the $2^{4}$ design can be found in Montgomery (pp. 331-334). Prior expectancy theory studies (e.g., Burton et al, 1992; Snead \& Harrell, 1995) also used one-half fractional factorial design.

3. In a pilot test, two different instruments were tested; each had the order of the cases determined at random. The two instruments were distributed to every other subject. The average $\mathrm{R}^{2} \mathrm{~s}$ from the two random-order versions were compared and found to have no significant difference between them. This result implies that there is no order effect in the experimental design.

4. This study adopts a within-person methodology that does not have a sample size requirement for making statistical inference. Prior studies (e.g., Burton et al., 1993; Geiger and Cooper, 1996), however, had a sample size of around 80.

5. A hierarchical regression analysis is conducted to compare the appropriateness of the full multiplicative model and the additive model. The only difference of the multiplicative model from the additive model is that the former incorporates not only the two independent variables, but also their interaction term. The results indicate that the average incremental explanatory power of the interaction term over the additive model is not significant. Thus, the additive model appears to be adequate in explaining the effort decisions.

6. It is reasonable to expect an association between someone's prior experience with an e-Learning technology and his/her motivation to adopt that particular technology. However, the students were asked to evaluate the 16 proposed cases (e-Learning technologies), but not the technology that they have experienced before. Therefore, the non-significant correlation coefficients indicate that the subjects are able to evaluate the proposed technologies objectively without bias. 


\section{References}

Anakwe, U. P., Kessler, E. H. \& Christensen, E. W. (1999). "Distance Learning and Cultural Diversity: Potential Users' Perspective," The International Journal of Organizational Analysis 7 (3), 224-243.

Armstrong, J. (2002). 'Effect of ICT on Students and Student learning,' Learning and Teaching Support Network Generic Centre.

Baker, W., Hale, T. \& Gifford, B. R. (1997). "From Theory to Implementation: The Mediated Approach to Computer-Mediated Instruction, Learning and Assessment," Educom Review 32 (5), 42.

Brownell, P. \& McInnes, M. (1986). "Budgetary Participation, Motivation, and Managerial Performance," Accounting Review 61(4), 587-600.

Burdman, P. (1998). Cyber U. Anaheim (California) Orange County Register, September 13, sec. 1, p. 9.

Burke, J. \& Slavin, N. (2000). "Just-in-Time Accounting Education," The CPA Journal, 70 (4), 47-51.

Burton, F. G., Chen, Y.- N., Grover, V. \& Stewart, K. A. (1993). "An Application of Expectancy Theory for Assessing User Motivation to Utilize An Expert System," Journal of Management Information Systems, 9 (3), 183-198.

Campbell, S. V., Baronina, T. \& Reider, B. P. (2003). "Using Expectancy Theory to Assess Group-Level Differences in Student Motivation: A Replication in the Russian Far East," Issues in Accounting Education, 18 (2), 125-136.

Chen, Y., Lou, H. \& Luo, W. (2002). "Distance Learning Technology Adoption: A Motivation Perspective," Journal of Computer Information Systems, 42 (2), 38-43.
Clark, R. E. (1983). "Reconsidering Research on Learning Support: An Online Resource Centre for A Diverse Student Population," Review of Educational Research, 53 (4), 445459.

Clerehan, R., Turnbull, J., Moore, T., Brown, A. \& Tuovinen J. (2003). "Transforming Learning Support: An Online Resource Centre for a Diverse Student Population," Education Media International, 40 (1-2), 15-32.

Collis, B. \& Moonen, J. (2001). Flexible Learning in a Digital World: Experiences and Expectations, Kogan Page, London.

De Lange, P., Suwardy T. \& Mavondo F. (2003). "Integrating a Virtual Learning Environment into An Introductory Accounting Course: Determinants of Student Motivation," Accounting Education: An International Journal, 12 (1), 1-14.

DeSanctis, G. (1983). "Expectancy Theory as Explanation of Voluntary Use of A Decision Support System," Psychological Reports, 52 (1), 247-260.

Dowling, C., Godfrey, J. M. \& Gyles N. (2003). "Do Hybrid Flexible Delivery Teaching Methods Improve Accounting Students' Learning Outcomes," Accounting Education: An International Journal, 12 (4), 373-391.

Dufresne, A. \& Turcotte, S. (1997). Cognitive Style and Its Implications for Navigation Strategies, Artificial Intelligence in Education: Knowledge and Media in Learning Systems, Boulay B. and Mizouguchi R. (Eds), Iospress, Amsterdam, 287-293.

Durling, D., Cross, N. \& Johnson, J. (1996). Personality and Learning Preferences of Learners in Design and Design-Related Disciplines. Paper Presented at the International Design and Technology Educational, Research and Curriculum Development Conference (IDATER 96), Loughborough University. 
Follows, S. B. (1999). "Virtual Learning Environments," Technological Horizons in Education Journal, 27 (4), 100-106.

Ford, N. \& Miller, D. (1996). "Gender Differences in Internet Perceptions and Use," Aslib Proceedings, 48 (1), 183-192.

Frey, A., Faul, A. \& Yankelov, P. (2003). "Student Perceptions of Web-Assisted Teaching Strategies," Journal of Social Work Education, 39 (3), 443-457.

Galitz, W. (2002). The Essential Guide to User Interface Design: An Introduction to GUI Design Principles and Techniques, 2nd Edition, John Wiley, New York.

Geiger, M. A. \& Cooper, E. A. (1996). 'Using Expectancy Theory to Assess Student Motivation,' Issues in Accounting Education, 11 (1), 113-129.

Griffith, T. L. (1996). "Negotiating Successful Technology Implementation: A Motivation Perspective," Journal of Engineering and Technology Management, 13, 29-53.

Hall, P. (1996). "Distance Education and Electronic Networking," Information Technology for Development, 7 (2), 75-89.

Hameed, S., Mellor, J., Badii, A., Patel, N. \& Cullen, A. J. (2007). "Factors Mediating the Routinisation of E-Learning Within a Traditional University Education Environment," International Journal of Electronic Business, 5 (2), 160.

Hancock, D. R. (1995). "What Teachers May Do to Influence Student Motivation: An Application of Expectancy Theory," The Journal of General Education, Fall, 171-179.

Harrod, W. L. \& Townsend, L. A. (1998). "Distance Learning in a Changing Environment at Lucent Technologies," Career Development International, 3 (5), 194-198.
Henry, P. (2001). "E-Learning Technology, Content and Services," Education \& Training, 43 (4/5), 249-255.

Holscherl, C. \& Strubel, G. (2000). "Web Search Behavior of Internet Experts and Newbies," Computer Networks, 33 (1), 337346.

Hopey, C. E. \& Ginsburg, L. (1996). "Distance Learning and New Technologies. You Can't Predict the Future but You Can Plan for It," Adult Learning, 8 (1), 22-23.

Hornik, S., Johnson, R. D. \& Wu, Y. (2007). "When Technology Does Not Support Learning: Conflicts Between Epistemological Beliefs and Technology Support in Virtual Learning Environments," Journal of Organizational and End User Computing, 19 (2), 23-47.

Ignatius, J. I. \& Ramayah, T. (2005). "An Empirical Investigation of the Course Website Acceptance Model (CWAM)," International Journal of Business and Society, $6(2), 69-82$.

Leung, E. W. C. \& Li, Q. (2006). "Distance Learning in Hong Kong," International Journal of Distance Education Technologies, 4 (3), 1-5.

Love, N. \& Fry, N. (2006). "Accounting Students' Perceptions of a Virtual Learning Environment: Springboard or Safety Net?," Accounting Education: An International Journal, 15 (2), 151-166.

Lucas, H. C. Jr. \& Spitler, V. K. (1999). "Technology Use and Performance: A Field Study of Broker Workstations," Decision Sciences, 30 (2), 291-311.

Maish, A. M. (1979). "A User's Behavior toward His MIS," MIS Quarterly, 3 (1), 39-52. 
Mayes, J. T. (2002). The Technology of Learning in a Social World, Supporting Life Long Learning: Volume 1 Perspectives on Learning, Harrison R. Et Al. (Eds), Routledge Falmer, London, 163-175.

Monaghan, P. (1995). "Technology and the Unions," Faculty Labor Leaders Air Hopes and Concerns as Colleges Enter the Electronic Era, The Chronicle of Higher Education, 41 (22), Sec. A17.

Montgomery, D. C. (1991). Design and Analysis of Experiments. John Wiley, New York.

Murray, D. \& Frazier, K. B. (1986). "A WithinSubjects Test of Expectancy Theory in a Public Accounting Environment," Journal of Accounting Research, 24 (2), 400-404.

Navarro, P. \& Shoemaker, J. (2000). "Performance and Perceptions of Distance Learners in Cyberspace," The American Journal of Distance Education, 14 (2), 15-35.

Nixon, J. C. \& Helms, M. M. (1997). "Developing the "Virtual" Classroom: A Business School Example," Education \& Training, 39 (9), 349-353.

O'Leary, R. \& Ramsden, A. (2002). Virtual Learning Environment, Learning and Teaching Support Network Generic Centre.

Ramsey, C. (2003). "Using Virtual Learning Environments to Facilitate New Learning Relationships," International Journal of Management Education, 3 (2), 31-41.

Robey, D. (1979). "User Attitudes and Management Information System Use," Academy of Management Journal, 22 (3), 527538.

Scalise, K., Bernbaum, D. J., Timms, M., Harrell, S. V., Burmester, K., Kennedy, C. A. \& Wilson, M. (2007). "Adaptive Technology for ELearning: Principles and Case Studies of an Emerging Field," Journal of the American
Society for Information Science and Technology, 58 (14), 2295-2309.

Snead, K. C. \& Harrell, A. M. (1994). "An Application of Expectancy Theory to Explain a Manager's Intention to Use a Decision Support System," Decision Sciences, 25 (4), 499-513.

Stahl, M. J. \& Harrell, A. M. (1981). "Modeling Effort Decisions with Behavioral Decision Theory: Toward an Individual Differences Model of Expectancy Theory," Organizational Behavior and Human Performance, 27 (3), 303-325.

Sun, P. C. \& Cheng, H. K. (2007). "The Design of Instructional Multimedia in E-Learning: A Media Richness Theory-Based Approach," Computers \& Education, 49 (3), 662-676.

Szajna, B. \& Scamell, R. W. (1993). "The Effects of Information System User Expectations on Their Performance and Perceptions," MIS Quarterly, 17 (4), 493-516.

Taylor, P. G. (2000). "Changing Expectations: Preparing Students for the Flexible Learning," International Journal of Academic Development, 5 (2), 107-115.

Vroom, V. C. (1964). Work and Motivation, John Wiley \& Sons, New York.

Wildstrom, S. H. (1997). 'The World Wide Classroom,' Business Week, August 18, P. 18.

Wreden, N. (1997). 'Long Distance Lessons Corporate America Is Finding That Distance Learning Is No Longer A Frill-It's a Ticket to Survival,' Communications Week, August 18, P. 41.

Xu, D. \& Wang, H. (2006). "Intelligent Agent Supported Personalization for Virtual Learning Environments," Decision Support Systems, 42 (2), 825-843. 
15 Journal of e-Learning \& Higher Education

Yang, N. \& Arjomand, L. H. (1999). "Opportunities and Challenges in ComputerMediated Business Education: An Exploratory Investigation of Online Programs," Academy of Educational Leadership Journal, 3 (2), 17-29.

Young, J. R. (1997). "Rethinking the Role of the Professor in an Age of High-Tech Tools," The Chronicle of Higher Education, 44 (6), Sec. A26-A28.

Zmud, D. E. (1980). 'The Role of Individual Differences in MIS Implementation Success,' Proceedings of the Twelfth Annual Meeting of the American Institute for Decision Sciences, 2, 215. 


\section{Appendix}

Assume that you are taking a course at a university and e-Learning (online learning) technology is introduced to the class and available for your use. Various outcomes may result from using the tool. For example, the eLearning technology may enhance learning effectiveness by:

(1) Facilitating acquisition, exchange and analysis of information (with features such as class notes, lecture, instructions, learning materials);

(2) Promoting student participation and active involvement in knowledge construction (with features such as homework, learning modules, interactive tutorials);

(3) Supporting collaboration and communication with classmates and professors (with features such as virtual chat room, discussion board, study group); and

(4) Providing dynamic feedback, cognitive diagnosis and score reporting (with features such as performance test, proficiency evaluation).

Use of this e-Learning technology is voluntary; your use could range from minimum to maximum. Minimum use essentially implies that you will conduct your class activities as you have been without the technology. Maximum use means that you will rely on the technology to a great extent for your class activities.

This exercise presents 16 situations. Each situation is different with respect to how the e-Learning technology is likely to be used. You are asked to make two decisions for each situation. You must first decide how attractive it would be for you to use the eLearning technology (DECISION A). Next you must decide how much effort to exert in using the technology (DECISION B). Use the information provided in each situation to reach your decisions. There are no "right" or "wrong" responses, so express your opinions freely. A sample situation is provided below. The 16 actual situations start on the next page.

\section{Sample Situation}

If you use the e-Learning (online learning) technology to the MAXIMUM extent in your class, the likelihood that the e-Learning technology will:

Facilitate acquisition, exchange and analysis of information is HIGH (90\%)

Promote participation and active involvement in knowledge construction is ........ HIGH (90\%)

Support collaboration and communication with classmates and professors is ...... HIGH (90\%)

Provide dynamic feedback, cognitive diagnosis and score reporting ................. LOW $(10 \%)$

DECISION A: With the above outcomes and associated likelihood levels in mind, indicate the attractiveness to you of using the online communication technology to enhance your learning effectiveness.

$\begin{array}{lllll}-5 & -4 & -3 & -2 & -1 \\ 0 & +1 & +2 & +3 & +4 \\ +5 & & & & \end{array}$

Very Unattractive $\quad$ Very Attractive

Further Information: If you exert a great deal of effort to use the e-Learning technology in your class activities, the likelihood that you will be successful in doing so is LOW $(10 \%)$ (The technology may be difficult to learn, has limited accessibility, or is not user friendly.) 
17 Journal of e-Learning \& Higher Education

DECISION B: Keeping in mind your attractiveness decision (DECISION A) and the FURTHER INFORMATION, indicate the level of effort you would exert to use the eLearning technology.

$\begin{array}{lllll}0 & 1 & 2 & 3 & 4 \\ 5 & 6 & 7 & 8 & 9 \\ 10 & & & & \end{array}$

Zero Effort

Great Deal of Effort 